\title{
Comparative Study of Access to Oral Health Care for Precarious and Non-precarious Populations in Abidjan, Côte d'Ivoire
}

\author{
Sangare Abou Dramane, ${ }^{1,}$, Samba Mamadou ${ }^{1}$, Meless Guanga David ${ }^{1}$, Adou Akpe Jonas ${ }^{3}$, \\ Traore Jules Fabrice ${ }^{2}$, Guinan Jean-Claude ${ }^{1}$, Bakayoko-Ly $\mathbf{R}^{1}$ \\ ${ }^{1}$ Department of Public Health, UFR Odonto-Stomatology, University FHB, Abidjan, Côte d'Ivoire \\ ${ }^{2}$ Group of Military Fire Brigade (GSPM) Abidjan, Côte d'Ivoire \\ ${ }^{3}$ Department of Conservative Dentistry Endodontics, UFR Odonto-Stomatology, Unvisersity FHB, Abidjan, Côte d'Ivoire
}

Email address:

sangare_aboudramane@yahoo.fr (S. A. Dramane)

${ }^{*}$ Corresponding author

\section{To cite this article:}

Sangare Abou Dramane, Samba Mamadou, Meless Guanga David, Adou Akpe Jonas, Traore Jules Fabrice, Guinan Jean-Claude, BakayokoLy R. Comparative Study of Access to Oral Health Care for Precarious and Non-precarious Populations in Abidjan, Côte d'Ivoire. International Journal of Health Economics and Policy. Vol. 4, No. 2, 2019, pp. 44-48. doi: 10.11648/j.hep.20190402.12

Received: March 6, 2019; Accepted: April 11, 2019; Published: May 10, 2019

\begin{abstract}
The objective of this study was to compare the dental status and the modalities of the use of oral care of people in precarious situations to those of non-precarious. A cross-sectional survey was conducted among 256 users of the dental office of the University Hospital of Treichville, in precarious situation or not. Subjects in precarious situations were identified using a tracking tool to take into account the context of the intervention. The respondents were interviewed using a standardized questionnaire. The data collected made it possible to calculate percentages and comparisons of the modalities of oral health care use between "precarious" and "not precarious" using the Chi2 test. Subjects in precarious situations had more recourse to self-medication $(84.6 \%)$ at first intention than subjects who were not precarious $(\mathrm{p}=0,011)$. Renunciation of oral health care was more common in the "precarious" group than in the "non- precarious" group $(\mathrm{p}=0,004)$. The number of missing teeth among people in precarious situations was twice as high as among "not precarious" subjects. On the other hand, the number of filled teeth (O) was 3 times higher in "not precarious" subjects than in "precarious" subjects. The results of this study show the need for awareness raising and the implementation of a social protection system guaranteeing greater accessibility to care for people in precarious situations and even for the population as a whole.
\end{abstract}

Keywords: Oral Health, Accessibility, Precariousness, Therapeutic Itinerary, Côte d'Ivoire

\section{Introduction}

Precariousness refers to the absence of one or more securities enabling individuals and families to assume their basic responsibilities and enjoy their fundamental rights [1]. This is a multifactorial phenomenon, a little known transitional situation because it is often confused with poverty. It is a source of insecurity, uncertainty and social instability leading to the fragility of the people who are victims. When it persists over time, precariousness leads to poverty (agg form) or even social exclusion and increases the obstacles to seeking care [2]. One of the consequences of this situation is the difficult access of these people to health [3, 4]. That is why, in the field of health, efforts are being made to support vulnerable people for the harmonious development of society. While there is no specific disease of "precariousness", some easily objectivable health indicators are found in this population with a high frequency and severity more marked than in the general population [2]. Thus, oral diseases are good indicators that reflect a lack of care, a lack of health culture and a lack of resources. Cohen in a study in the United States showed that disadvantaged people have limited access to dental care and even when they 
do, they give up access to it [5]. This means that the situation of insecurity resulting from precariousness requires that attention be paid to the oral health of people in this situation. While much work has been done in Côte d'Ivoire on the issue of people's access to oral health care [6-9], precariousness as a risk factor for oral morbidity is not sufficiently documented [10]. This deprives decision-makers of valuable information for comprehensive care of people's oral health with a focus on social justice. In this context, it seemed appropriate to us to know the dental status of people in precarious situations and of the "not precarious" in Côte d'Ivoire and to understand the rationale for using oral health care for these two groups of populations. Thus, the objective of this study was to compare the dental condition and oral health care utilization patterns of these individuals.

\section{Methods}

\subsection{Type and Area of the Study}

The transversal study with an analytical focus was carried out at the dental office of the Treichville University Hospital Centre, a commune located in Abidjan, the economic capital of Côte d'Ivoire.

\subsection{Study Population, Selection Criteria, Sample Size}

The eligible population was dental practice users between May and October 2012, who were at least 18 years old at the time of the survey. Two comparison groups ("Precarious" and "Non-precarious") were set up based on the identification tool developed on the Hassoun model [11] and incorporating the precariousness criteria defined by the poverty reduction strategy paper of the republic of Côte d'Ivoire [12]. This tool includes five questions related to: the minimum daily amount to live (1.5 USD/day), the possession of health insurance, the ability to pay for medicines and medical examinations, the existence of a fixed residence for the user and his employability situation since the last 6 months. People in precarious situations were identified according to the answers given to the questions in this tracking tool. Thus, was considered to be in a precarious situation, a person living with less than 1.5 USD/day, not having a fixed address, looking for a job, not having health insurance or having difficulty in meeting medical and pharmaceutical expenses. All patients coming for dental consultations were systematically subjected to this identification tool after their agreement. When a user met the precariousness criteria, he or she was selected to be part of the study and immediately afterwards, the 2 nd user to be recruited had to be a person who was not in a precariousness situation, and so on. This method of recruitment made it possible to identify 128 socalled "precarious" patients and 128 so-called "nonprecarious" patients over the duration of the collection period (5 months).

\subsection{Data Collection and Variables Studied}

The data were collected by a single calibrated interviewer, using a standardized survey form consisting of a questionnaire and an oral clinical examination form. All patients coming for dental consultations were systematically subjected to this identification tool after their agreement. When a user met the precariousness criteria, he or she was selected to be part of the study and immediately afterwards, the 2 nd user to be recruited had to be a person who was not in a precariousness situation, and so on. The questionnaire covered general information related to socio-demographic characteristics, oral health behaviours and financial accessibility to care. The second part related to the urgency or otherwise of the dentist's consultation and the dental check-up (number of decayed, missing or filled teeth). Once consent was obtained, patients were first subjected to the questionnaire and then to the oral clinical examination.

\subsection{Data Analysis}

The data collected were calculated in terms of numbers and frequencies. The Chi2 test was used to investigate the link between social precariousness and the modalities of care use and the respondents' oral health status. The relationship between the parameters studied was considered significant for $\mathrm{p}<0.05$.

\section{Results}

\subsection{Socioeconomic Parameters}

Table 1. Socioeconomic characteristics of respondents.

\begin{tabular}{|c|c|c|c|}
\hline \multirow[t]{2}{*}{ Variables } & $\begin{array}{l}\text { Precarious } \\
(\mathrm{N}=128)\end{array}$ & $\begin{array}{l}\text { Non-precarious } \\
(\mathrm{N}=128)\end{array}$ & \multirow[t]{2}{*}{$\mathbf{p}$} \\
\hline & n (\%) & n (\%) & \\
\hline Sex & & & 0.005 \\
\hline Male & $42(32.8)$ & $65(50.8)$ & \\
\hline Female & $86(67.2)$ & $63(49.2)$ & \\
\hline Age (years) & & & 0.057 \\
\hline $18-30$ & $73(57.0)$ & $56(43.8)$ & \\
\hline $31-45$ & $48(37.5)$ & $67(52.3)$ & \\
\hline$>45$ & $7(5.5)$ & $5(3.9)$ & \\
\hline Level of education & & & 0.005 \\
\hline Not in school & $10(7.8)$ & $0(0.0)$ & \\
\hline Elemantary & $21(16.4)$ & $16(12.5)$ & \\
\hline Secondary & $39(30.5)$ & $52(40.6)$ & \\
\hline Superior & $58(45.3)$ & $60(46.9)$ & \\
\hline Professional activities & & & 0.000 \\
\hline Yes & $72(56.3)$ & $99(77.3)$ & \\
\hline No & $56(43.7)$ & $29(22.7)$ & \\
\hline
\end{tabular}

The results show a significant difference between precarious and non-precarious for the gender $(p=0.005)$, educational level $(\mathrm{p}=0.005)$ and professional activity $(0.000)$ variables. The number of women is higher among those in precarious situations than among the "not precarious". The "not precarious" have a higher level of education overall than that of people in precarious situations. As a result, the number of people without professional activities is higher in the group of socially vulnerable people. 


\subsection{Therapeutic Itinerary}

Table 2. Sample distribution by therapeutic use.

\begin{tabular}{llll}
\hline \multirow{2}{*}{ Type of recourse } & $\begin{array}{l}\text { Precarious } \\
(\mathbf{N = 1 2 8 )}\end{array}$ & $\begin{array}{l}\text { Non-precarious } \\
\mathbf{( N = 1 2 8 )}\end{array}$ & \multirow{2}{*}{$\mathbf{p}$} \\
\cline { 2 - 3 } & $\mathbf{n} \mathbf{( \% )}$ & $\mathbf{n}(\mathbf{\%})$ & \multirow{2}{*}{0.011} \\
\hline Public dental office & $14(10.9)$ & $32(25.0)$ & \\
Private dental office & $6(4.7)$ & $7(5.5)$ & \\
Self-medication & $108(84.4)$ & $89(69.5)$ & \\
\hline
\end{tabular}

The choice of a therapeutic itinerary is significantly related to the social status of the respondents $(p=0.011)$. Respondents reported increased use of self-medication as a first-line treatment. This practice is more pronounced among the precarious.

Table 3. Frequency of dental care use.

\begin{tabular}{llll}
\hline & Precarious (N=128) & $\begin{array}{l}\text { Non-precarious } \\
(\mathbf{N = 1 2 8 )}\end{array}$ & \multirow{2}{*}{$\mathbf{p}$} \\
\cline { 2 - 3 } & $\mathbf{n}(\mathbf{\%})$ & $\mathbf{n}(\mathbf{\%})$ & \\
\hline Never & $36(28.1)$ & $18(14.0)$ & 0.004 \\
This year & $23(18.0)$ & $33(25.8)$ & \\
Less than 2 years & $10(7.8)$ & $23(18.0)$ & \\
More than 2 years & $59(46.1)$ & $54(42.2)$ & \\
\hline
\end{tabular}

The frequency of oral health care use is significantly related to the patient's social status $(\mathrm{p}=0.004)$. The number of subjects who had never used a dentist was higher among the "precarious" (28.1\%) than among the "not precarious" $(14.0 \%)$.

Table 4. Distribution of respondents by type of care received.

\begin{tabular}{llll}
\hline \multirow{2}{*}{ Type of care } & Precarious $(\mathbf{N = 1 2 8 )}$ & $\begin{array}{l}\text { Non-precarious } \\
(\mathbf{N = 1 2 8})\end{array}$ & \multirow{2}{*}{$\mathbf{p}$} \\
\cline { 2 - 3 } & $\mathbf{n}(\mathbf{\%})$ & $\mathbf{n}(\mathbf{\%})$ & 0.389 \\
\hline Emergency care & $99(77.3)$ & $92(71.9)$ & \\
No emergency care & $29(22.7)$ & $36(28.1)$ & \\
Total & $128(100 \%)$ & $128(100 \%)$ & \\
\hline
\end{tabular}

There was no significant difference between social status and emergency consultations. Both people in precarious situations and those who were not in precarious situations preferred to consult for emergency care.

\subsection{Oral Status of Respondents}

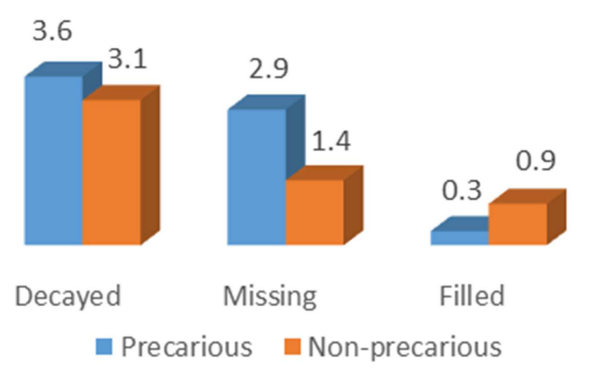

Figure 1. Distribution of indices of decayed, missing and filled teeth in patients in precarious or non-precarious situations.

People with precariousness overall have a worse dental outcome than non-precarious ones. The caries index was higher in the precarious than the non-precarious ones, that of the missing teeth was 2 times higher in the people in precarious situation than in the "non-precarious" subjects. On the other hand, the index of filled teeth $(\mathrm{O})$ was 3 times higher in "not precarious" subjects than in "precarious" subjects.

\section{Discussion}

The comparative study of the dental situation and the modalities of the use of oral care between people in precarious situations and those who were not precarious, made it possible to tackle a major problem of public health, in particular that of access to care for vulnerable people. This study showed that people in precarious situations had difficulty accessing oral health care and poor dental health. Also, it presented an important challenge: that of targeting people in situations of social precariousness given the complexity of this phenomenon. The identification of these people was carried out according to well-defined criteria adapted to the context of Côte d'Ivoire. In a study conducted in France, the main criterion used to identify people in precarious situations was the employment situation. Indeed, the unemployed over six months of age, the "Rmis", unemployed 16 to 25 year olds and non-students were considered as "precarious"[2]. However, in our study, the collection of information based on the declarative mode could be a limit of the study. Nevertheless, the sample of the study without being representative of the two types of populations studied, still makes it possible to compare the logics of recourse to the oral care of populations in different economic and social situations. Moreover, the composition of this sample $59 \%$ of women and $41 \%$ of men, corroborates the study carried out in Abidjan in 2002 in the surgery department of the Odonto-Stomatological Consultations and Treatments Center, which showed that women had more use of oral care than men [13]. This same observation was made in France in a study carried out in 2003 with the adult population of the Paris region [14]. Thus, the results of this study showed that precariousness seemed to concern women more than men $(67.2 \%$ versus $32.8 \%)$. This situation would explain why the abandonment of dental care for financial reasons is more observed in women than in men in Côte d'Ivoire [15]. In the literature, the low level of education and the absence of employment seem to be good predictors of precariousness [10]. In our study, there was a link between precariousness, lack of employment $(\mathrm{p}=0.000)$ and low educational attainment (0.005). This fact is in line with the survey conducted in France on oral health and precariousness, where $87 \%$ of people in precarious situations did not have a stable job [16]. This instability of employment or its absence leads to fragility of people in precarious situations with consequences for the therapeutic use of oral health. Thus, our study showed that people in precarious situations had more recourse to self-medication than nonprecarious people even if for both groups, self-medication was the first recourse in oral health care. This result 
corroborates that of the study carried out in Abidjan where, in the absence of a social protection mechanism for the entire population, $69 \%$ of the 404 household heads surveyed reported using self-medication as first-line of oral affection [17]. The financial fragility of people in precarious situations often leads them to give up oral health care [18] or to resort to subsidized public health facilities as attested by the study conducted among adults in Thailand [19]. In our study, the number of people in precarious situations who gave up oral care was twice as high as the non-precarious. A study conducted in Côte d'Ivoire in 2003 showed that this phenomenon of giving up dental care was more observed in urban than rural areas because of the financial obstacle [15]. The financial barrier has proved to be the main obstacle to access to oral health care in both Côte d'Ivoire [20] and Senegal [21]. This requires the implementation of prepayment and cost-sharing mechanisms in order to pool the financial risk. The difficulties people face in meeting the costs of care can be the source of late consultations. In fact, more than two-thirds of those surveyed in both precarious and non-precarious cases had recourse to the dental surgeon for emergency care with painful symptomatology. When oral diseases are not managed within the required time, they can lead to complications. A study conducted in India on the reasons for late oral care in patients with oral cancer had identified the main barriers as: the lack of awareness (97\%), the hope that the lesion will heal spontaneously (90\%), lack of perception of gravity (64\%), financial constraints [22]. This late recourse to oral health care, which is more prevalent among the precarious, seems to have a negative impact on their oral health compared to the non-precarious, thus establishing a strong link between precariousness and poor oral health. The index of decayed teeth was higher in precarious than in non-precarious (3.6 vs 3.1), that of missing teeth, twice as high and the index of closed teeth in precarious was half of that of the non-precarious. This same observation was made by Beylet and Menahem in their study on the oral health of people in precarious situations in France with significant needs in oral care [16]. However, the development of an equitable oral health system that improves health outcomes and responds to legitimate demands from populations through equitable funding is considered to be one of the main strategic implications of the WHO oral health program [23]. Efforts remain to be made mainly in developing countries to prevent people in precarious situations from falling into poverty which would further complicate the situation. In that the two-way relationship between poverty and poor health is well established. Poverty breeds poor health and poor health maintains poverty [24].

\section{Conclusion}

Reducing inequalities in oral health among different socioeconomic groups is one of the main global goals of oral health. This study has shown that people in precarious social situations, have more difficulties of access to care and therefore a worse state of oral health than non-precarious ones. Improving the oral health of the population and especially people in precarious situations requires awareness of the importance of an oral state for good general health. Therefore, the establishment of a social protection system ensuring greater financial accessibility to oral health care is necessary to remove the financial obstacle. The goal of universal health coverage, which implies quality care for all the population regardless of the social situation to which Côte d'Ivoire aspires, must take into account the poor by adapting the provision of care to their needs.

\section{Authors' Statement}

The informed consent of the respondents was obtained prior to their participation in the study. Each study participant was briefed on the study objective and confidentiality was assured for any information provided.

\section{References}

[1] High Committee of Public Health France. News and Dossier in Public Health No 12, 1995/09.

[2] Hassoun D. Precariousness and oral health status. Health Economics Newsletter 1998; 16.

[3] Moradell M, Halley Des Fontaines V. The main risks of exclusion from care in the European Union countries. Public Health 2000; 12: 513-26.

[4] Schneider-Bunner C. Health and Social Justice: The Economics of Health Systems in the Face of Equity. In-depth collection of economic knowledge. Paris: Economica; 1997.

[5] Cohen LA. The role of non-dental health professionals in providing access to dental care for low-income and minority patients. Dent Clin N Am 2009; 53(3):451-58.

[6] Samba M., N'zoré K. S., Da-Danho V., Guinan J. C., Bakayoko-Ly. Evaluation of the financial accessibility of 350 users of public oral health services in the city of Abidjan. Rév. Iv. odonto-stomatol. 2004. 6(2): 52-54.

[7] Samba M., Sangaré A. D., N'zoré K. S., Guinan J. C., Bakayoko-Ly R. Oral health attitudes of a population in disadvantaged urban areas in Abidjan. Rev. Col OdontoStomatol. Afr. Chir. Maxillo-fac. 2007; 14(3): 5-9.

[8] Sangaré AD, Samba M, Bourgeois D. Illness-related behaviour and sociodemographic determinants of oral health care use in Dabou, Côte d'Ivoire. Community Dent Health. 2012; 29(1): 78-84.

[9] Sangaré AD, Samba M, Meless GD, Guinan JC, Bakayoko-Ly R, Bourgeois D. Crossing perspectives on the use of modern and traditional oral care in Côte d'Ivoire. Rev. Col Odonto-Stomatol. Afr. Chir. Maxillo-fac. 2013, 20(3): 5-11.

[10] Nugent ZJ, Longbottom C, Pitts NB. Quantifying dental inequality - developing the methodology. Community Dent Health 2002; 19: 43-5.

[11] Hassoun D. Precariousness and state of oral health. Thesis Chir dent. Univ Paris 7. CREDES, library n ${ }^{\circ} 1249,60 \mathrm{p}$. 
[12] Ministry of Planning and Development Côte d'Ivoire. Poverty Reduction Strategy Paper: Development Recovery and Poverty Reduction Strategy January 2009.

[13] Nouaman NM. Activity report of the CCTOS Department of Surgery and Odontostomatological and Maxillofacial Pathology January 1995-December 1997, Th Chir-Dent, UFR Odonto-Stomatol, Univ. Cocody, Abidjan 2005.

[14] Vincelet C, Azoguy-Lévy S, Grémy I. Inequality in oral health in the adult Francilian population, 2002-2003. Bull Epidemiol Hebdo 2009; 15: 137-41.

[15] Sangaré AD, Samba M, Guinan JC, et al. Socio demographic factors associated with renunciation to oral care in Côte d'Ivoire. MOJ Public Health. 2017; 6(1): 241-248.

[16] Beynet A, Menahem G. Dental problems and precariousness. Health Economics Newsletter, 2002; 48.

[17] Samba M, Guinan J-C, Sangaré AD. Therapeutic itinerary in odonto-stomatology in Abidjan. Odontostomatol Trop. 2004; 27(107):37-40.

[18] Borges Da Silva G, Minguet-Fabbri J, Orgebin JY, Herter G, Chanut C, Mabriez JC. Quality of dental care and social inequalities in health. Rev Med Ass Maladie 2002; 33 (3): 193-200.
[19] Somkotra T, Detsomboonrat P. Is there equity in oral healthcare utilization: experience after achieving Universal Coverage. Community Dent Oral Epidemiol 2009; 37: 85-96.

[20] Samba M, Kouadio NGA, Guinan JC, et al. The renunciation of oral care in Abidjan. Rev. Col. Odonto-Stomatol Afr Chir Maxillo-fac. 2003; 10: 52-57.

[21] Lo CM, Cissé D, Faye D, et al. Factors associated with the abandonment of oral health care in Senegal. Oral Public Health Letter. 2010; 1:8-11.

[22] Rath H, Shah S, Sharma G, Mishra E. Exploring determinants of care-seeking behaviour of oral cancer patients in India: A qualitative content analysis. Cancer Epidemiol. 2018; 53:141148.

[23] Petersen PE. The World Oral Health Report 2003: continuous improvement of oral health in the 21st century - the approach of the WHO Global Oral Health Programme. Community Dent Oral Epidemiol 2003; 31(Suppl. 1): 3-23.

[24] Wagstaff A. Poverty and health sector inequalities. Bull World Health Organ. 2002; 80(2):97-105. 